\title{
Tree Risk Assessment with Sonic Tomograph Method at Bali Botanical Garden
}

\author{
Siti Fatimah Hanum ${ }^{1 *}$, I Dewa Putu Darma ${ }^{1}$, Muhammad Bima Atmaja ${ }^{1}$, Gebby Agnessya Esa Oktavia ${ }^{2}$ \\ 'Eka Karya Bali Botanic Garden, Research Center for Plant Conservation and Botanic Garden - Indonesian Institute of \\ Sciences, Candikuning, Baturiti, Tabanan, Indonesia 82191 \\ ${ }^{2}$ Purwodadi Botanic Garden, Research Center for Plant Conservation and Botanic Garden - Indonesian Institute of Sciences, \\ Pasuruan, Indonesia 67163
}

Received April 2, 2020/Accepted October 7, 2020

\begin{abstract}
Safety perception is the most important part of people's choice in determining tourist sites. Standing trees that are prone to falling are very dangerous for both visitors and employees. Standing tree with decay wood inside is often the cause of tree failure. Therefore, there is a need for research examining the risk of collection and non-collection trees in Bali Botanical Garden. Tree risk checks were carried out using the Tree Risk Assessment method from the International Society of Arboriculture (ISA), which has been modified. The result of this research gives valuable information for the manager to determine tree handling to minimize tree risk.
\end{abstract}

Keywords: Acoustic Tomograph, tree risk assessment, public space, ArborSonic 3D Tomograph, decay level

*Correspondence author, email: siti030@lipi.go.id, tel.+62-368-2033211,fax.+62-368-2033171

\section{Introduction}

Botanical Gardens are ex-situ plant conservation areas with a plant collection of data arranged according to taxonomic classification, bioregion, thematic, and a combination of these patterns with the aim of conservation activities, research, education, tourism and environmental services (PP RI Number 93/2011). Bali "Eka Karya" Botanical Garden (BBG) is an institution that carried out exsitu conservation of dry highland plants. BBG carries out the functions of carrying out plant exploration, managing plant collections, researching and developing plant collections, and carrying out services and information (Perka LIPI Number 5/2016). In his vision, BBG mentioned providing services in aspects of botany, environmental education, horticulture, landscaping, and tourism (Darma \& Hanum, 2007). BBG is one of the tourist attractions with the highest visits, reaching more than 500,000 visitors in 2015 (Muntadliroh, 2016). Hence, urban communities also prefer to relax and pay more in public places with many trees (Dwyer et al., 1989).

The existence of trees provides advantages and disadvantages. Trees have economic value and ecological benefits. As the tree's growth, the benefits of economic value and ecological are increasing. Benefits from the presence of trees include providing shade from sunlight and wind barrier, managing rainwater into surface water, reducing air pollution through the uptake of pollutants by leaves, increasing property values, providing a positive effect on human psychological health, providing shade and food for wildlife and increasing the use of shaded asphalt roads (Hauer \&
Johnson, 2003). However, the existence of trees can also be dangerous. The accident of fallen trees is unpredictable, although many measurements have been carried out (Lazim \& Misni, 2016). Failure trees or parts of trees can break and cause material damage or physical injury (Hauer \& Johnson, 2003). Tree risk is defined as a tree with structural damage that can cause trees or parts of trees to fall. This damage can result in material and non-material losses. The risk of a tree can vary from low to high. This risk is determined by the damage that will be occurred. A low-risk tree is a tree that can lose its branches in locations where there are no physical damage and human injury. While a high-risk tree is a tree located in areas with high human activity and valuable properties (Hauer \& Johnson, 2003)

As a conservation institution, BBG has more than 20,000 plant specimens (Registration, 2020). The plant collections in BBG consists of trees, shrubs, herbs, and climbing plants. BBG has been established since 15 July 1959 (Muntadliroh, 2016), so it has many old collections. Tree collections over 50 years old have a higher risk of falling traits such as weathering, broken branches, cracks and hollow stems (Raihandhany \& Kurniawati, 2016)

Several years ago, tree species in Bogor Botanical Garden had structural damage caused by termites that injured several visitors (Zuhri et al., 2018). This case proves that trees are prone to falling are very dangerous for both visitors and employees. Therefore, perceptions about safety are the most important part of people's choices in determining tourist locations (Schroeder, 1990). To provide safety locations, trees conditions must be checked regularly, from 
outside and inside of the tree. Visual tree assessment was used to examine the tree's condition from outside, slenderness ratio used to examine tree resistance from wind blow. In contrast, sonic tomography is used to examine inside tree conditions.

ArborSonic acoustic 3D Tomograph is one example of non-destructive commercial equipment (Li et al., 2016). This equipment uses stress waves, which produce manually from hammer tapping on one pin to each other pin to detect wood decay inside the tree (Loon et al., 2018). Stress wave velocity measured in trees has also been found effective to detect moderate to severe decay in Cibodas and Bogor Botanical Garden (Helmanto et al., 2018; Rachmadiyanto et al., 2019; Zuhri et al., 2018). The objective of this research was to assess tree risk in the public area at Bali Botanical Garden. The result of this research will help the BBG manager to arrange tree priority handling.

\section{Methods}

Location and time The study was conducted at BBG from May to August 2016. The research location was selected by purposive sampling based on the level of visits of group visitors who rented locations in the botanical garden (Figure 1).

Tools and materials The equipment used is a set of ArborSonic 3D Acoustic Tomograph equipment (sensors, hammers, and computers connected to arbosonic), diameter tape, roll meter $(30 \mathrm{~m})$, digital cameras, Nikon Forestry Pro (Laser Rangefinder) and Microsoft Excel 2010.

Visual observation of tree conditions Tree risk checks were carried out using the modified Tree Risk Assessment Form from the International Society of Arboriculture (ISA) (Figure 2). Samples were observed as many as 497 trees with

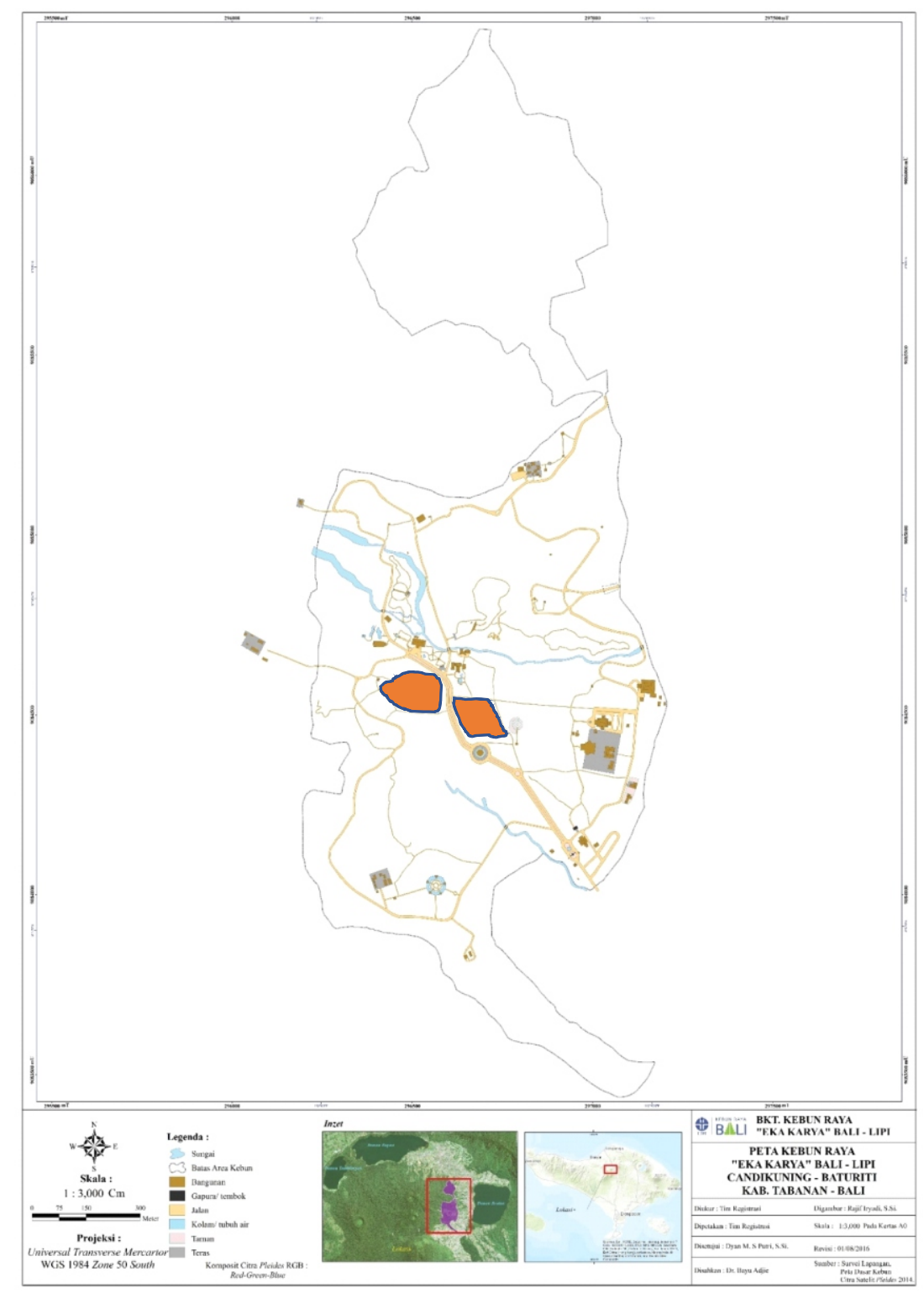

Figure 1 The map of research location (brown color) at Bali Botanical Garden. 
diameter breast height $>40 \mathrm{~cm}$. This sample consists of the collection and non-collection trees. A collection tree is a tree with data information, while a non-collection tree is an existing tree in the garden without data information. Tree morphological characters observed were tree height measured by Nikon Forestry Pro (Laser Rangefinder); tree canopy width measured by roll meter and diameter at breast high (DBH) measured by diameter tape. Visual observation of tree trunks' condition was also done by looking at the outermost trunk of the sample tree, especially to see whether there were any symptoms or signs of deterioration. Observation of the tree's visual condition will support the results of the examination using ArborSonic. The results of visual observations are recorded on the observation sheet. We use the scoring number from 13 for each parameter, then calculate the score from each parameter (Table 1). A tree with the highest scoring number will be analyzed by further check using ArborSonic 3D Acoustic Tomograph.

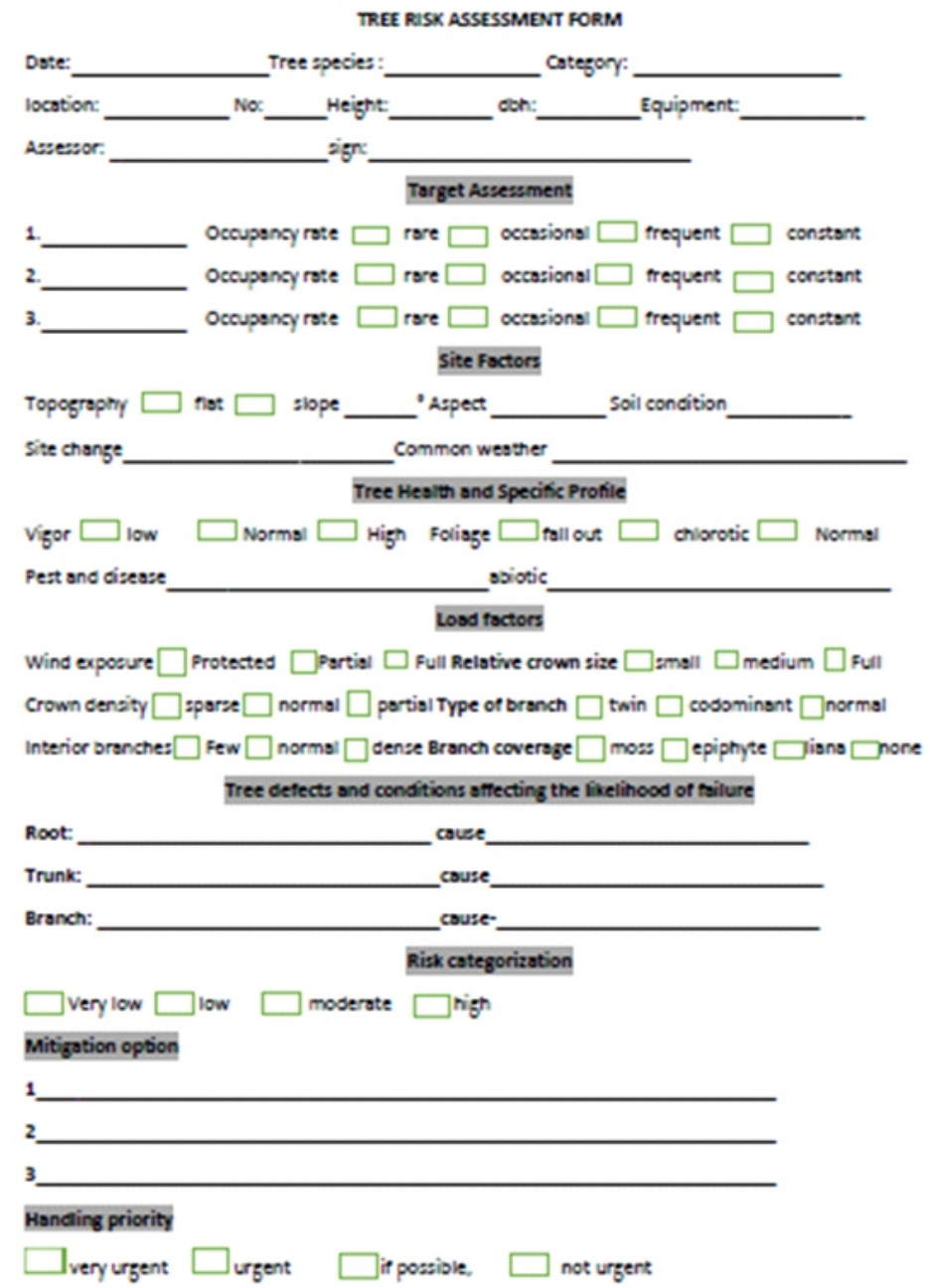

Figure 2 Modified ISA risk assessment form.

Table 1 Tree risk scoring from Tree Risk Assessment Form

\begin{tabular}{llll}
\hline Parameter & Score $=1$ & Score $=2$ & Score $=3$ \\
\hline Occupancy rate & Occasional & Frequent & Constant \\
Topography & Flat & Slope $<45^{\circ}$ & Slope $>45^{\circ}$ \\
Soil condition & Soil & Partial pavement & Full pavement \\
Wind exposure & Protected & Partial & Full \\
Crown density & Sparse: $1-33 \%$ & Normal: $34-66 \%$ & Dense: $67-100 \%$ \\
Type of branch & Normal & Codominant & Twin \\
Branch coverage & None/only moss/ & Moss + epiphyt $/$ moss + & Moss + epiphyt+liana \\
& epiphyte/liana & liana/epipyht+liana & \\
\hline
\end{tabular}

Note: Tree risk scoring: low $=7-11 ;$ middle $=12-16 ;$ high $=17-21$ 
Selection of sample trees for arbosonic measurements The selection of tree samples was carried out by purposive sampling with criteria for tree trunk diameters $>40 \mathrm{~cm}$, having epiphyte load or branching off, or there were signs of damage due to pests and diseases, located in an area that was visited by tourists. Thus, a total of 44 trees were sampled in this study.

Evaluate wood decay inside the tree using ArborSonic Checking the internal condition of each sample tree trunk is done using the ArborSonic 3D Acoustic Tomograph tool. The step to use ArborSonic 3D were: (1) drive eight sensors perpendicular to the trunk with the equal distance in counterclockwise order (Figure 3A); (2) connect the sensors to the amplifier boxes then connect the amplifiers in a line. Connect the battery box on any end of the line then connect to PC; (3) each sensor was tapped with a steel hammer to generate sound waves; (4) the software was calculated and displayed the internal sound-velocity distribution of the tree (Figure 3B). To get accurate information about the internal trunk condition, it is important to assess the tree in several layers (Figure 3C). The level of tree risk is obtained from the maximum percentage of decay level. The observations are grouped into three groups: low-risk trees with characteristic parts of the tree appearing intact (Figure 4), medium tree risk with characteristic features of trees appearing to decay (Figure 5) and high tree risk, trees with hollow or hollow insides (Figure 6). ArborSonic measurement results determine the type of tree handling. Trees with a high priority will get immediate treatment and special treatment (regular monitoring) compared to trees with low priority. Trees with high priority are trees located in densely populated areas, have large trunk diameters, are aged, or are seen to be attacked by pests and diseases (Helmanto et al., 2018).

Determination of tree-level damage using ArborSonic is done based on Helmanto et al., (2018) which classifies high risk if the percentage of wood decay is above $60 \%$, moderate risk if the percentage of wood decay is between $30-60 \%$ and low risk if the percentage of wood decay is below $30 \%$.

Slenderness ratio Tree slenderness is an important characteristic of shade tree resistance to wind and rainstorm

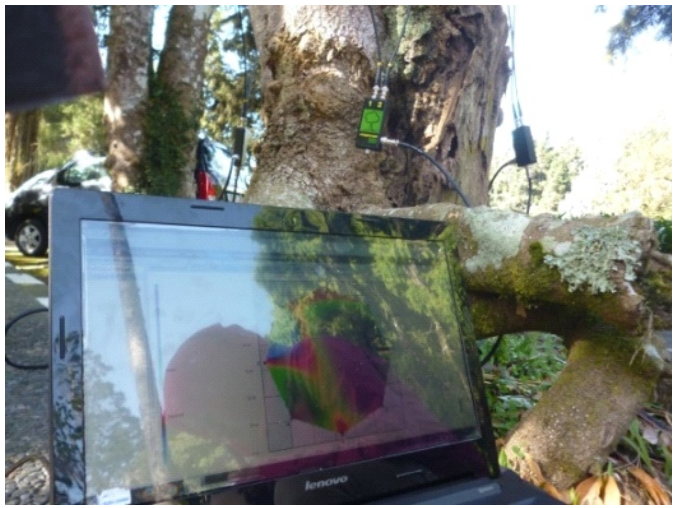

B

A

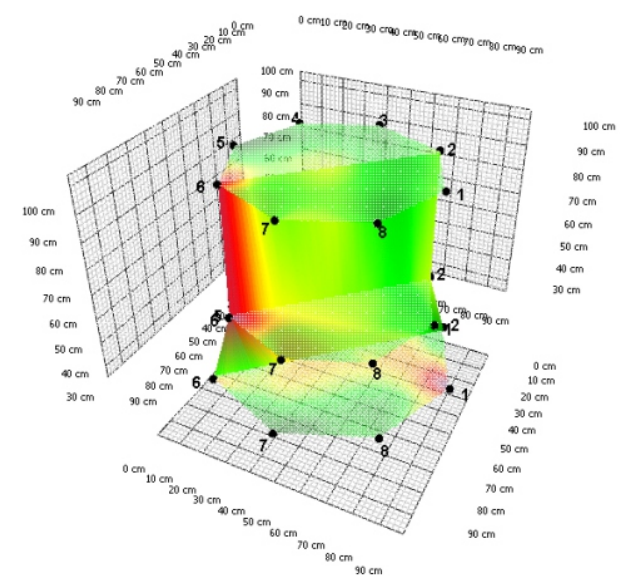

$\mathrm{C}$

Figure 3 Arbosonic equipment installation around tree trunks (A), The result will be shown in the computer (B), The threedimensional appearance of the trunk examined, the $\mathrm{x}$-axis indicates the height of the pinned metal mounted (C). 
(Puspitasari, 2014). Tree slenderness is obtained from a ratio between height (h) and the diameter of the tree at breast height (Dbh) (Adeyemi \& Adesoye, 2016). This ratio is a good indicator describing the optimization of biomechanical systems in plants (Jelonek et al., 2012). The optimum value for the slenderness ratio is between 25-50; trees with a slenderness ratio of more than 50 have a greater risk of fallen trees (Mattheck \& Bethge, 2011). While Adeyemi \& Adesoye, (2016) have different criteria in determine slenderness ratio as high $>80$; moderate; 70-80 and low: $<70$.
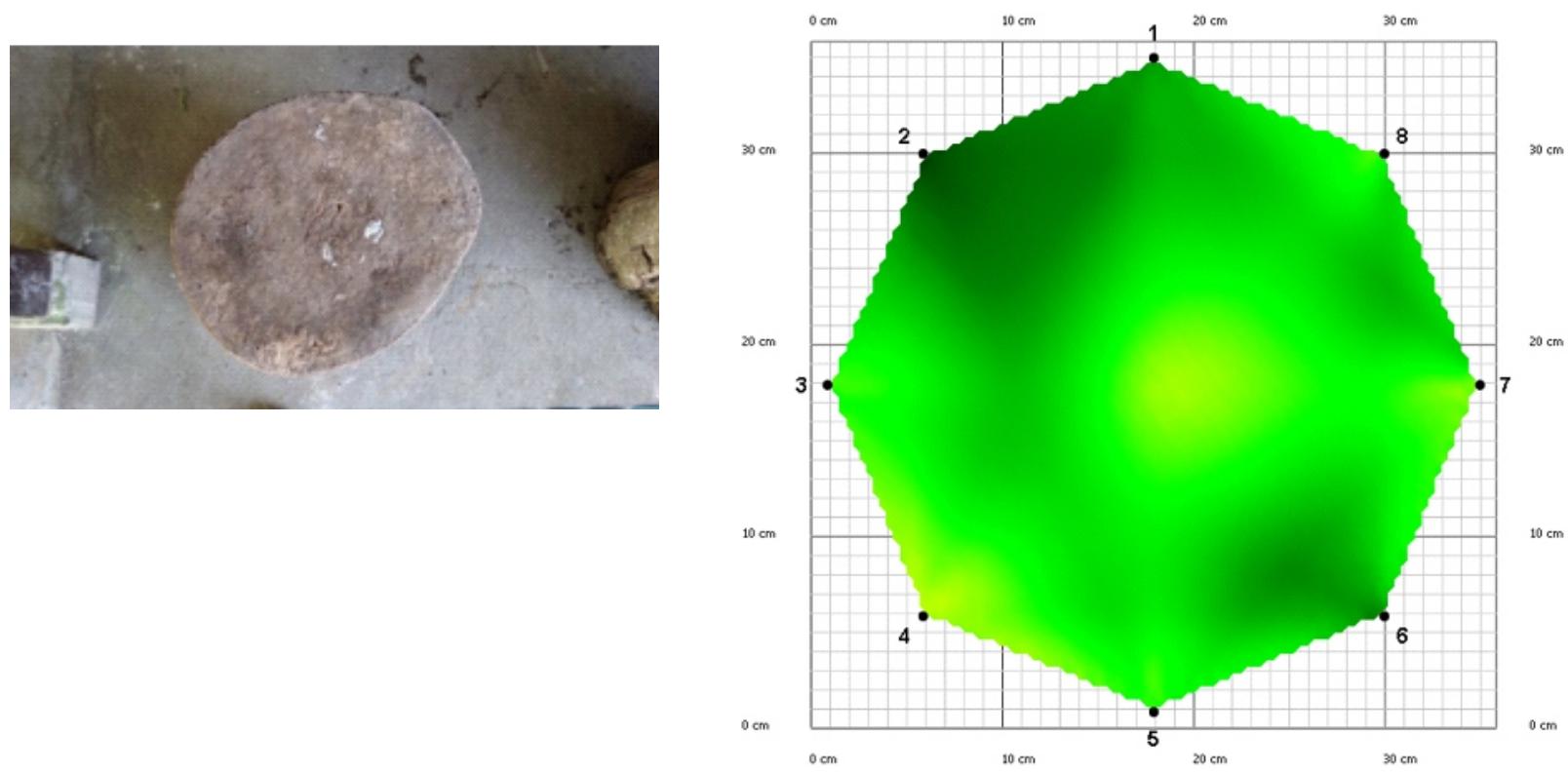

Figure 4 Inside tree trunk show good condition with green color.
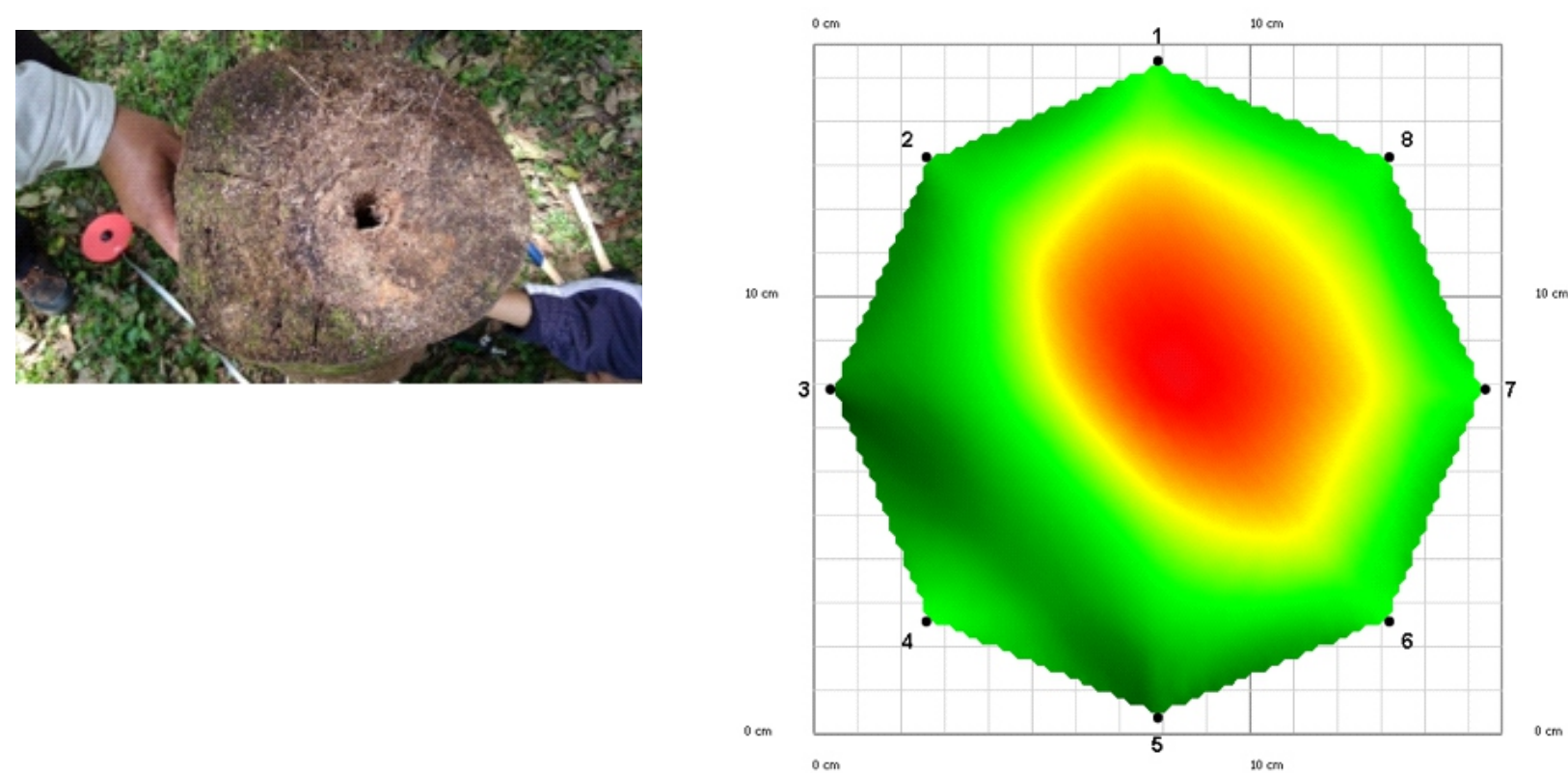

Figure 5 Inside tree trunk show decayed condition which represented with yellow and red color. 

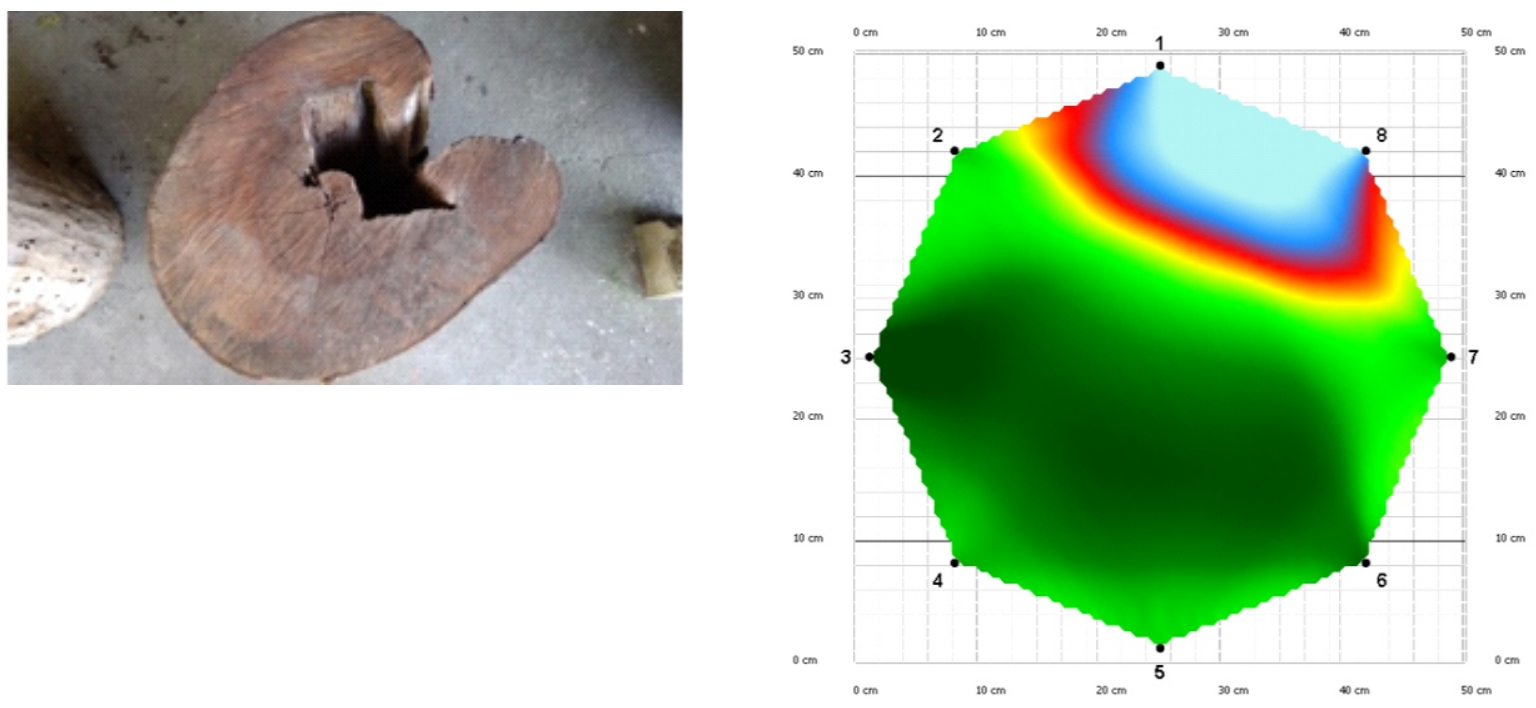

Figure 6 Inside tree trunk show hollow represented with blue color.

\section{Results and Discussion}

Tree risk assessment From 497 trees observed, there were 170 trees with low risk and 327 trees with moderate risk (Figure 7). High-risk trees were not found in this observation. This is because the assessment only focusses on visual observation, which cannot detect high-risk damage to the tree.

Since visual observation results are not enough, a further check with ArborSonic acoustic 3D tomography is done for selected trees. The results showed that seven trees were classified as high-risk trees comprise of Casuarina junghuhniana, Enterolobium timbouva (two trees), Toona sureni, Cinnamomum burmanni, Cupressus arizonica, and Ehretia javanica., seven moderate risk trees comprise of Cupressus lusitanica (two trees), Enterolobium timbouva, Cinnamomum camphora, Araucaria sp., Prunus puddum, and Cinnamomum camphora, and 24 low-risk trees comprises of the remain sample tree (Table 2). Determination of tree-level damage using ArborSonic is done based on Helmanto et al., (2018) which classifies high risk if the percentage of tree damage is above $60 \%$, moderate risk if the percentage is between $30-60 \%$ and low risk if the percentage of hollow trees is below $30 \%$. Mostly the highest percentage of wood decay occurred on ground level or at the base of the trunk (Table 2). This result similar to Makys et al. (2018), who mention that wooden poles fixed in and covered up with soil are the most damage after checked with sonic Tomograph.

Height and diameter tree able to determine the slenderness ratio. According to slenderness ratio classification by Mattheck \& Bethge, (2011), Syzygium polyanthum, Causarina junghuhniana, Araucaria cunninghamii and Araucaria heterophylla has a higher risk of fallen trees than other trees because it has a ratio more than 50 (Table 2). This result is higher compare with Pterocarpus indica, which has a ratio below 50 (Puspitasari, 2014). Besides the slenderness ratio, the type of tree also determines

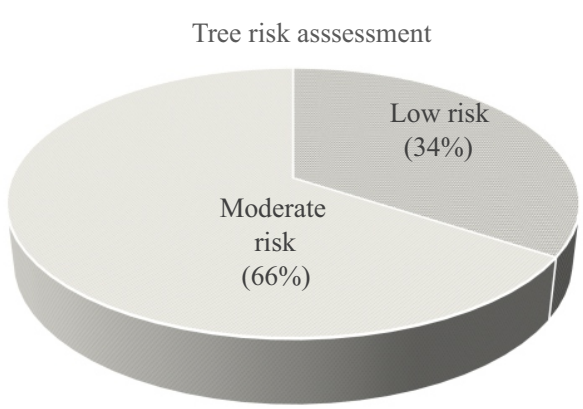

Figure 7 Proportion of tree risk based on visual observation.

the resistance to the winds. Jelonek et al. (2012) stated that the type of needle leaf (scots pine) that grows in northern Poland forests is still considered stable despite having a slim value of 66-81. This means Casuarina junghuhniana, Araucaria cunninghamii, and Araucaria heterophylla in Bali Botanical Garden still considered stable compare with Syzygium polyanthum. Casuarina and Araucaria have a needle leaf type, while Syzygium polyanthum has a broadleaf.

Furthermore, tree morphological character such as tree slenderness and canopy diameter have a weak relation with ArborSonic inspection results. Trees with a high risk based on ArborSonic do not have a high tree slenderness ratio, whereas trees with low risk based on ArborSonic have a high tree slenderness ratio (Table 2). The correlation between the slenderness ratio and the level of risk is weak because $R^{2}=$ $0.28, p<0,1$. However, when correlating between tree canopy diameter and ArborSonic result checked, there is also a week correlation because $R^{2}=0.02, p<0.1$. This is because ArborSonic only detects the percentage of wood decay inside the trunk based on species character. This result also in line with Zuhri et al. (2018), who said even the tree visually shows the poor condition, not always correlate with ArborSonic result. 


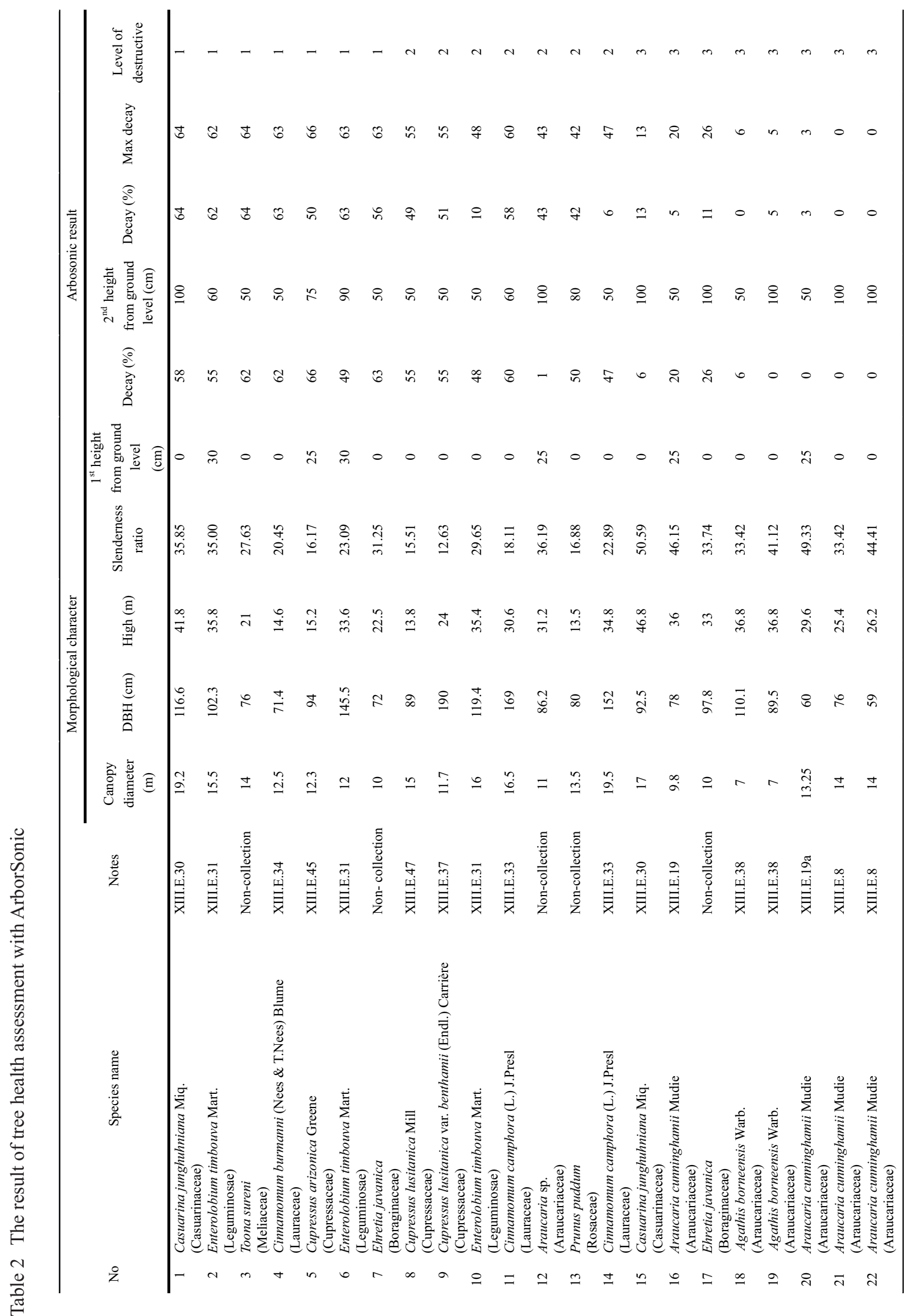




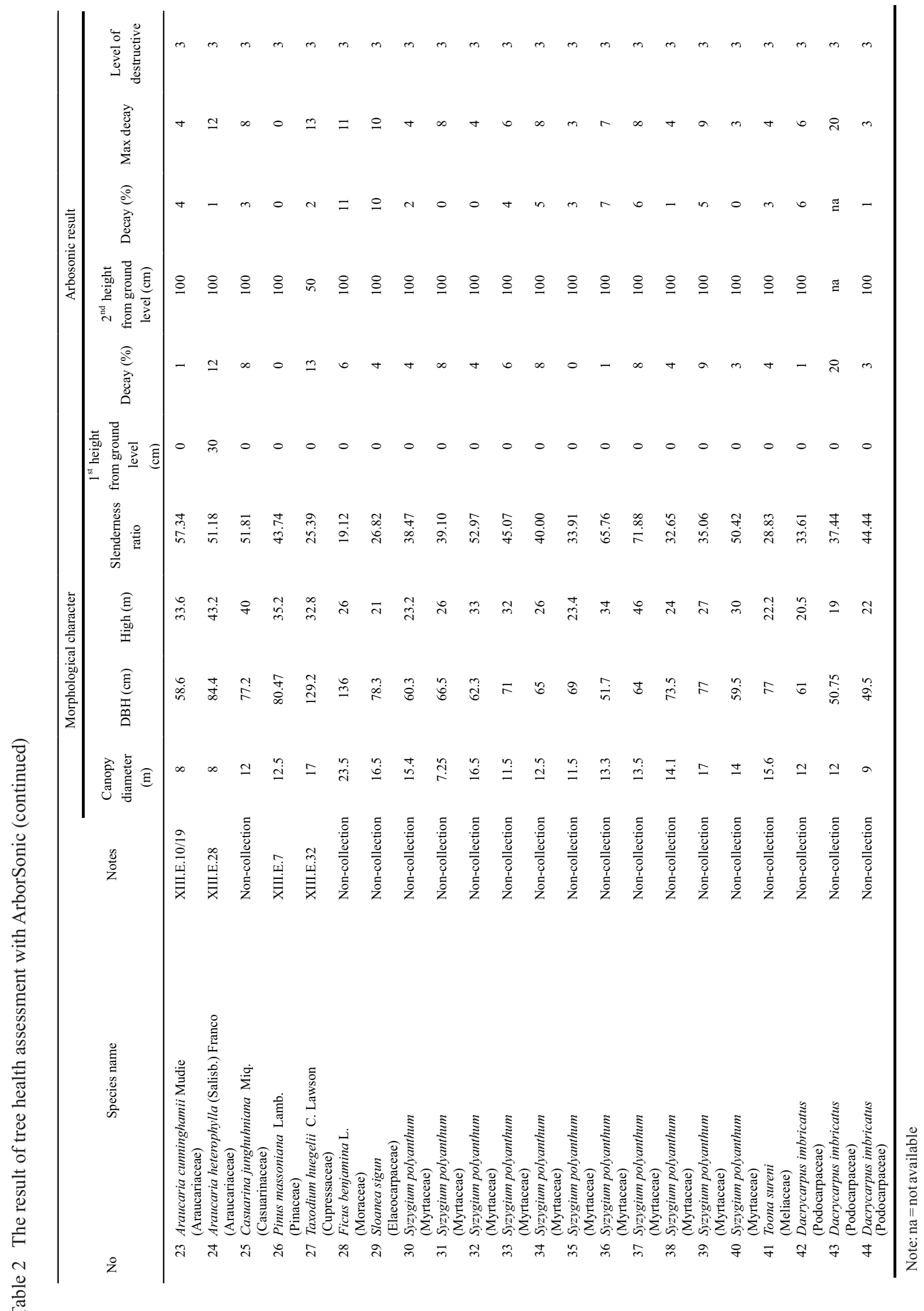


Trees with visual assessment from high-risk tree exhibit symptoms of deterioration such as the weathered trunk, moist trunk, codominant and have a litter in tree branches and have hollow in the base of the tree trunk (Table 3) Only one high-risk tree shows a healthy trunk, that is Toona sureni from Meliaceae family. Since we cannot find damage on the trunk, we suggest wood termite and borer attack cause the hollow inside trunk. This pest is common to attack Toona sureni (Lemmens, 1995). However, ArborSonic measurement will support visual assessment results.

Cause of tree failure There are many ways for trees to fail. According to Albers et al. (2003), a fail tree occurs when the load (weight and canopy motion) exceeds the mechanical strength of a branch, trunk, or root system. Some fail tree incidents lead to fallen trees or broken tree branches in BBG due to root problems and branch problem (Figure 8). This is following Albers et al. (2003), who mention that a fail tree can be predicted because the sign of damage indicates that the part of the tree will fail. There are seven signs of damage to trees, namely: rotted wood, crack, root problems, cancer (areas where the bark or cambium dies), poor tree architecture, weak branch unions, dead trees/branches.
Plant collection in BBG is mostly obtained from the forest in seedling, then acclimatize in the nursery at BBG. During acclimatization, the seedlings are planted in polybags. This practice may cause root growth disrupted, especially in taproots. Therefore, plant collection which grows in the field will have shallow root. Then when strong winds come, this will lift the shallow root tree (Figure 8B). Pokorny (2003) states that $84 \%$ of trees' damage caused by windstorms already had signs of previous damage to trees and branches. One effort to avoid the catastrophic effect of strong winds is by planting trees in groups rather than individuals.

Furthermore, the cause of fallen trees in BBG is weak branch unions' support with termite attack. A tree with more than two branches has the potency to fail one of these branches. Figure 8A shows that a branch of Joannesia princeps has falled. This incident was alleged because of weak branch unions' support due to termite attack. We suggest it from the symptom, such as a presence of tunnels inside the base of the trunk.

Moreover, some tree also has an epiphyte plant on a limb and cause weathering. This limb susceptible to fall when the strong wind. This result is in line with Puspitasari (2014),

Table 3 Visual assessment of high-risk tree with ArborSonic

\begin{tabular}{ll}
\hline Name of species & Visual Assessment \\
\hline Casuarina junghuhniana & Weathered trunk \\
Enterolobium timbouva Mart. & Codominant, and has litter in tree branches \\
Toona sureni & Healthy trunk \\
Cinnamomum burmanni (Nees \& T.Nees) Blume & Hollow in the base of tree trunk \\
Enterolobium timbouva Mart & Codominant \\
Cupressus arizonica & Dry limb \\
Ehre tia javanica & Hollow in the base of the tree trunk \\
\hline
\end{tabular}

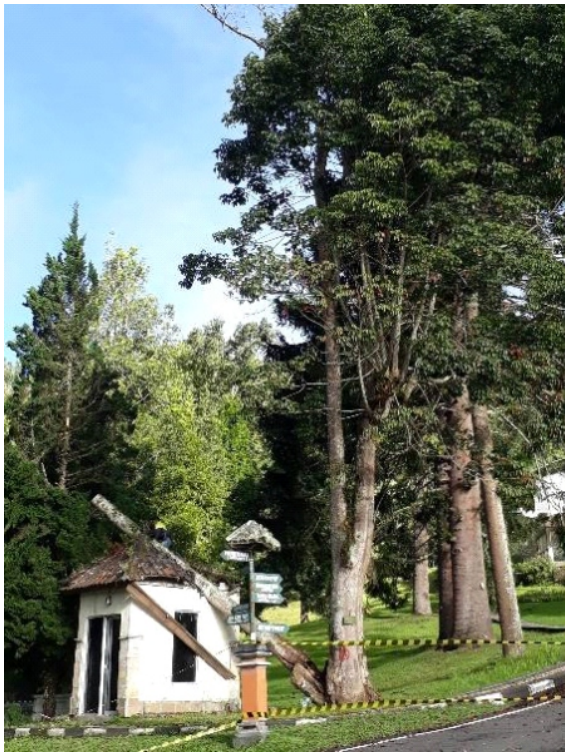

(A)

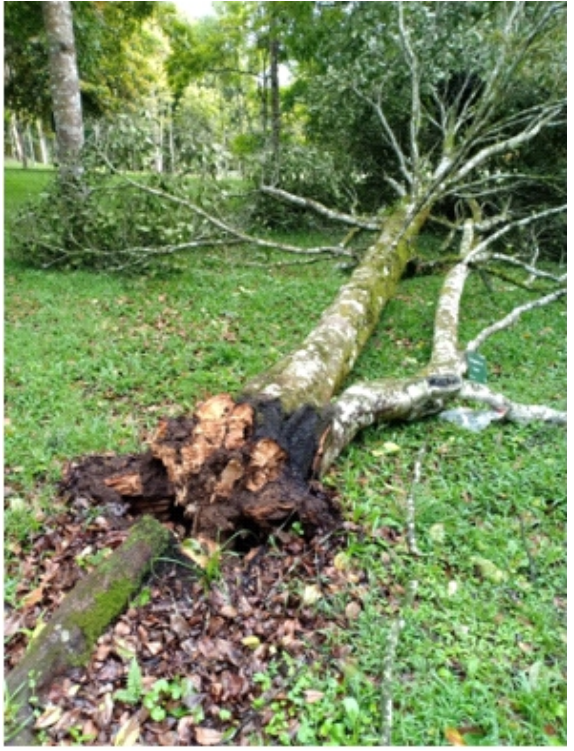

(B)

Figure 8 Fail branch of Joannesia princeps (A) and uproot tree (B). 
which mention weathering also found as the most visual deterioration in Pterocarpus indicus at Surabaya street. Ephyphite plant on the tree will cause weathering in the tree surface for a long period.

Tree risk management A failure tree is unpredictable. Therefore regular tree risk management is mandatory. Tree risk management consists of tree risk inspection and tree risk assessment. This is an activity that started with visual tree assessment and continues with ArborSonic measurement. For high-risk locations, inspections are carried out more often than low-risk locations. Strategies to reduce high-risk trees in the public area are moving targets such as benches and installing dangerous tree signs. Pokorny (2003) states that tree risk management should be integrated with planting, pruning, tree maintenance, and rapid response activities. Several things that can be done to avoid losses due to failure trees started from choosing the quality of the plant, correct planting technique, proper pruning technique, and protect trees from damage to construction (Johnson et al., 1999).

\section{Conclusion}

Modern technology can be used to minimize the risk of tree failure to individual injury and property. Visual assessment is not enough to detect a failure tree. Therefore, ArborSonic measurement will support visual assessment. Tree risk assessment initiated with tree inspection and continue with ArborSonic measurement is suggested to be done regularly, especially in the public area. The result of tree assessment classified location into high-risk, moderate-risk, and low-risk. Strategies to reduce high-risk trees in public areas are by moving targets such as benches and installing high-risk tree signs.

\section{Acknowledgment}

The author would thank Ahmad Fauzi and Harully Merriansyah from Bali Botanical Garden, who has given technical support during this research. Finally, thanks to reviewers for their valuable comments on the manuscript and editorial team for its support.

\section{References}

Adeyemi, A., \& Adesoye, P. (2016). Tree slenderness coefficient and percent canopy cover in Oban Group Forest. Journal of Natural Sciences Research, 6, 9-17.

Albers, J. S., Pokorny, J. D., \& Johnson, G. R. (2003). How to detect and assess hazardous defects in trees. In J. D. Pokorny (Ed.), Urban Tree Risk Management: A Community Guide to Program Design and Implementation (pp. 41-76). USDA Forest Service Northeastern Area.

Darma, I. D. P., \& Hanum, S. F. (2007). Thematical collection arrangement analysis at Bali Botanical garden. Warta Kebun Raya, 10-14.

Dwyer, J. F., Schroeder, H. W., Louviere, J. J., \& Anderson, D. H. (1989). Urbainities willingness to pay for trees and forests in recreation areas. Journal of Arboriculture, 15(10), 247-252.
Hauer, R. J., \& Johnson, G. R. (2003). Tree risk management. In J. D. Pokorny (Ed.), Urban Tree Risk Management: A Community Guide to Program Design and Implementation (pp. 5-10). USDA Forest Service Northeastern Area.

Helmanto, H., Kristiati, E., Wardhani, F., Zulkarnaen, R., Sahromi, Mujahidin, ..., \& Abdurachman. (2018). Tree health assessment of Agathis borneensis Warb. in Bogor Botanical Garden using arborsonic. IOP Conference Series: Earth and Environmental Science, 203, 012032. https://doi.org/10.1088/1755-1315/203/1/012032

Jelonek, T., Tomczak, A., \& Grzywinski, W. (2012). Biomechanical stability of pines growing on former farm land in Northern. Wood Research, 57(1), 31-44.

Johnson, B. G. R., Hauer, R. J., \& Pokorny, J. D. (1999). Prevention of hazardous tree defects. In J. D. Pokorny (Ed.), Urban Tree Risk Management: A Community Guide to Program Design and Implementation (Vol. 1, pp. 117-142). USDA Forest Service Northeastern Area.

Lazim, R. M., \& Misni, A. (2016). Public perceptions towards tree risk management in. Procedia-Social and Behavioral Sciences, 222, 881-889. https://doi.org/10. 1016/j.sbspro.2016.05.210

Lemmens, R. H. M. J. (1995). Toona sureni (Blume) Merr. In R. H. M. Lemmens, I. Soerianegara, \& W. C. Wong (Eds.), Plant resources of South-East Asia. Timber trees: Minor commercial timbers (Vol. 5, p. 655). Leiden: Backhuys.

Li, G., Weng, X., Du, X., Wang, X., \& Feng, H. (2016). Stress wave velocity patterns in the longitudinal - radial plane of trees for defect diagnosis Stress wave velocity patterns in the longitudinal - radial plane of trees for defect diagnosis. Computers and Electronics in Agriculture 124, 23-28. https://doi.org/10.1016/j.compag.2016.03. 021

Loon, C., Abdul, R., Hafiz, M., Rahiman, F., Tunnur, M., Talib, M., \& Cong, Z. (2018). Sensors and actuators A: Physical sensing wood decay in standing trees: A review. Sensors \& Actuators: A. Physical, 269, 276-282. https://doi.org/10.1016/j.sna.2017.11.038

Makys, O., Krusinsky, P., Korenkova, R., \& Srobarova, D. (2018). Diagnostics of wooden poles situated in the openair museum using sonic tomography, 14(1), 54-60. https://doi.org/10.2478/cee-2018-0007

Mattheck, C., \& Bethge, K. (2011). A new multi-purpose tool for tree diagnosis. https://doi.org/10.5445/IR/220085 200

Muntadliroh. (2016). Strategi komunikasi pemasaran terpadu ekowisata di Kebun Raya Eka Karya, Bedugul Bali. Jumpa, 3(1), 40-59.

Pokorny, J. D. (2003). Urban tree risk management: A 
community guide to program design and implementation. USDA Forest Service Northeastern Area.

Puspitasari, D. A. I. (2014). Evaluation of shade trees of angsana (Pterocarpus indicus Willd.) based on sonic tomography in Surabaya. Bogor: Bogor Agricultural University.

Rachmadiyanto, A., Helmato, H., Rinandio, D., \& Abdurachman. (2019). Tree health analyzing of Malvaceae collections in Bogor Botanical Gardens. IOP Conference Series: Earth and Environmental Science, 298, 012017. https://doi.org/10.1088/1755-1315/298/1/ 012017

Raihandhany, R., \& Kurniawati, F. (2016). Tree risk assessment at Cibodas Botanical Garden with tree risk assessment method from ISA (International Society of
Arboriculture). In Seminar Nasional Biodiversitas VI, (pp.991-998). Surabaya, September 3, 2016.

Registration, U. (2020). The number of plant living collection and herbarium in July 2020 (monthly report, unpublished).

Schroeder, H. W. (1990). Perceptions and preferences of urban forest users. Journal of Arboriculture, 16(3), 58-61.

Zuhri, M., Sunandar, D., Rustandi, U., NAdhifah, A., Kurniawati, F., \& Iskandar, E. (2018). The detection of wood decay of trees collection Agathis borneensis and Castanopsis argentea at the public area in Cibodas Botanical Garden. IOP Conference Series: Earth and Environmental Science, 203, 012034. https://doi.org/ $10.1088 / 1755-1315 / 203 / 1 / 012034$ 